\title{
Ethics, Dementia and Severe Communication Problems
}

\author{
Erna Alant ${ }^{1,2}$ \\ ${ }^{1}$ Department of Curriculum \& Instruction, Indiana University, Bloomington, USA \\ ${ }^{2}$ Center for AAC, University of Pretoria, Pretoria, South Africa
}

\section{Email address:}

ealant@gmail.com

\section{To cite this article:}

Erna Alant. Ethics, Dementia and Severe Communication Problems. Humanities and Social Sciences. Special Issue: Ethical Sensitivity: A Multidisciplinary Approach. Vol. 4, No. 2-1, 2016, pp. 37-40. doi: 10.11648/j.hss.s.2016040201.16

Received: October 29, 2015; Accepted: January 3, 2016; Published: May 13, 2016

\begin{abstract}
Emmanuel Levinas [1] argued that ethics cannot be regarded as a set of principles, rules or norms, but rather that the fundamental basis of ethics is communication and negotiated decision-making. This article explores the conditions necessary for ethical behavior to occur, as explored by Murray [2], by focusing on two relevant issues: firstly the ability of the individual to announce themselves, i. e. their ability to open up or share of themselves, and secondly, their ability to represent themselves in issues surrounding decision-making. These two issues will be explored by referring to people with severe dementia and those who have severe communication problems. The paper includes the voice of the individual as well as the voice of those who interact with individuals with severe communication problems.
\end{abstract}

Keywords: Ethics, Dementia, Severe Communication Problems

\section{Introduction}

Ethics usually denotes values or conceptions of desirable behavior which form a basis for making choices and judgments. Ethical issues thus arise when the behavior of one individual impacts another, involving a conscious choice by the individual in terms of making a judgment based on his/her own set of values of right and wrong [3, 4]. This process firstly implies a sound understanding of the impact of the individual's actions on the Other and secondly a personal set of values in judging right and wrong. However, the issues surrounding ways in which an individual's behavior can impact on others and the process by which individuals make ethical judgments based on their own set of values are most complex. This article sets out to identify some of these complexities insofar as they relate to communication and interactions involving individuals with severe memory and communication problems.

In an article published in The New York Times [7] entitled "Our Irrational Fear of Forgetting", Margaret Gullette, a scholar at the Women's Studies Research Center at Brandeis University, states that "[i]n our hyper cognitive society, fear of forgetfulness has made deep inroads into the psyche". She describes the anxiety surrounding Alzheimer's and the common perception that it robs sufferers of selfhood, due to memory loss and cognitive degeneration. Michael Verde, President of Memory Bridge (www.memorybridge.org), responded by stating that perceiving Alzheimer's in this way could have more to do with "the pyramids of Egypt than a genuine concern for suffering" [5]). Verde's seeming flippancy underscores his contention that our framing of people with Alzheimer's may have more to do with our anxieties about our own mortality and an ensuing denial of death, than it does with any genuine investment in understanding the existential condition of people said to have Alzheimer's - in understanding "where they are" in a place of living experience. Verde's discussion concludes by emphasizing the necessity of extending ourselves emotionally to people with Alzheimer's, of empathetically attuning ourselves to their emotional needs, desires and concerns; however "unrealistic" these may seem according to our own "reality".

Mental and emotional ability can survive mere memory loss, as do other qualities that make us human. However, if our criteria of what constitutes "being here" is existentially reductive and artificially circumscribed to our definition of "rationality"; then such surviving qualities will miss our attention and recognition, both individually and socially [6]. Therefore, this argument [6] emphasizes the necessity of extending ourselves emotionally to offer companionship to 
people with Alzheimer's and to reflect on the ethical issues entailed in our perceptions of Alzheimer's and how these impact on the lives of the individuals and families involved.

Considering that families differ significantly in terms of how they view and respond to people with Alzheimer's what is the ethical way for professionals and families to deal with those who systematically lose their cognitive (in particular memory) abilities? Jeffrey Murray [2] in Face to Face in Dialogue describes ethics and communication as a transformation from "the ethics of communication", where one has a set idea of what is ethical or not, to "the communication of ethics", in which one accepts that ethics fundamentally requires communication and negotiated decision-making. The philosopher Emmanuel Levinas [1] argued that ethics cannot be conceived of as a pre-existing set of principles, rules or norms, but that they are instead a moral summons that is elicited from outside of an individual and that unsettles the individual's principles, rules, norms and ways of seeing the world. Levinas asserts that one's responsibility for the Other is infinite, and therefore ethics necessarily originates or comes from the external. One, therefore, has an obligation to engage with alterity. This approach to ethics emphasizes the responsibility to engage "the Other", which in this Alzheimer's scenario is not only the family, but also the individual with Alzheimer's. In the case of Alzheimer's (and individuals with severe communication problems) this approach implies one's responsibility to engage with the affected individual in exploring the ethical solutions to issues. How then does one act ethically if a person has a severe memory and/or communication problem?

There are two relevant issues here: firstly, what are the conditions that are required to allow a person with Alzheimer's to participate or, to use Levinas' term, "announce" themselves? And secondly, if an individual has severe memory loss are they able to represent themselves adequately?

Murray [2] discusses the conditions necessary for "ethics" to occur. He states that the prerequisite for ethical behavior and decision-making to occur requires resources for communication, for its effective announcement. "Announcement", here, refers to the processes of opening up or the sharing of oneself in order to engage with others. This "announcement or call" often requires effective communication strategies in order to be heard over cultural assumptions, stereotypes, prejudices and prejudgments. Therefore, a call for ethics should form the starting point of an interaction with others; while also requiring an understanding of the communication process necessary for ethical behavior to occur. Rather than simply preceding communication, ethics is reconceived as an announcement that is dependent upon communication. It requires an awakening or resuscitation from suffocating prejudice and prejudgment, hence the communication of ethics. In our scenario, this would require that we engage the person with Alzheimer's, regardless of the difficulties involved in facilitating participation on their terms, i. e. "where they are at". Clearly, this engagement could be dramatically different from their past interactions prior to developing Alzheimer's. But then, could this apparent "los[s] of selfhood" [7] not make it impossible to ascertain what the person really wants?

\section{2. "Being with" and Communication}

Murray [2] refers to the paradoxical nature of Levinas' theory: first that "the face" (in French, visage - used to signify not the body, but the living presence of another person, the "being") appears, and second that justice is possible. The face of another can never appear (i. e. one can never fully understand the other) it also cannot be reduced to the self's perception. In this sense, the face does not appear; though at the same time, the face does appear (albeit in a limited way). It appears, but never as an object for knowledge. It appears not as knowledge (in the past tense, as something to be "said"), but in the "being" (engaged in the present, in the act of "saying") or moment of approach. The face to face encounter is therefore not an attempt of the self or "I" to know the world, but rather a calling to which the "I" must respond. Access to the face is not through perception or knowing, but through a call which is "straightaway ethical", i. e. the conscience to know that others need to be engaged.

In our application to Alzheimer's this implies firstly, in that "the face" or the living presence of another is not easy to define, as individuals are complex and the individual's self is multi-dimensional. Getting to know someone, developing companionship, is thus not contingent on "knowing or understanding" the person, but rather on "being" with them. While an object presents itself to consciousness; persons present themselves to the individual's conscience as a moral summons. So the face of the Other does not appear as something to be known; rather it appears as a summons to be acknowledged and engaged. Murray [2] describes how communication has often served to overwrite the face, and how communication might serve to recover it. Communication can mask, and become rhetoric that overshadows the self. Similarly, however, the capacity for rhetoric to challenge and disrupt cultural discourses does not "announce" the face, but rather lifts the veil (factors that obscure our perceptions) to allow us to encounter the Other. This highlights the necessity of engaging with the person with Alzheimer's, even though it could be difficult and uncomfortable.

How then is justice possible, if it is to be negotiated in this context? "If I am alone with the Other, I owe him everything; but there is someone else. There is thus a necessity to moderate this privilege of the Other" [2, p xii]. Although Levinas stresses our responsibility to the Other, he highlights at the same time that there are other Others (in French, le tiers, or the "third party"). The fundamental fact that one is obligated to the Other is not open for debate, and one cannot elude or escape that obligation. But the definition of the Other clearly also includes more than just the individual and family. In fact, it reaches further to include the broader definition of "other"; in our example this constitutes the 
broader societal perception of Alzheimer's.

From the above discussion, it becomes evident that the engagement of individuals and "others" is pertinent for ethical or just action to occur. However, what is equally, if not more, evident is how difficult this process of communication can be. In this regard, Levinas again differentiates between rhetoric and discourse. Rhetoric is self-serving and manipulative, promoting the self over the Other. The problem is not that it is false, but that it is partisan, remaining trapped within the self's own "point of view". This self-centeredness is a problem, even if it is not conceived of as being intentionally manipulative in that it inhibits or denies "genuine conversation" (discourse), an original relation with an "exterior being" [2, p. 51]. The Other is able to express himself in discourse without having to limit himself to a particular point of view. It is, therefore a genuine form of communication, a way of experiencing the Other without reducing, negating or totalizing the Other's otherness. Levinas expands on these ideas by describing eloquence and everyday language. Eloquence or stylistic aspects "seduces the listener in comparison with the straightforwardness of everyday speech" [2, p. 53); thus Levinas differentiates between distorted and undistorted forms of communication. To be ethically responsive, communication must be initiated by the "undistorted first word of the Other", authentic expression devoid of manipulation - in whatever way this expression manifests and in whatever form it takes.

A problem with this approach is, however, that the means of communication is not so easily distinguished from the ends they can achieve. Neither rhetoric nor eloquence are inherent enemies of ethics - ineloquent language can silence people as effectively as stylistic language. The real issue relates to how rhetoric and dialogue might facilitate the acknowledgement of and engagement with the Other. So rather than distinguishing between rhetoric and conversation or everyday language and eloquence, the challenge that Murray [2] identifies relates to how communication can identify, challenge, and reconstitute itself to more adequately acknowledging and engaging the Other.

One of central issues in "communication of ethics" relates to the ability to "be with" the Other in a way that allows one to engage not only on an emotive level, but also as a means to allow the face of the Other to appear; thus for the Other to share of him/herself to allow for justice to occur. The ability to be emotively with another is therefore not sufficient. The Other also needs to "announce themselves", or in more practical terms, be able to express themselves, sharing thoughts and ideas to allow others to see the face appear. It is towards this aim that the field of Augmentative and Alternative Communication (AAC) promotes the use of infrequently used modes of communication (e. g. manual signs, low-tech communication boards and communication technology) to allow people with severe communication problems to supplement their existing communication skills to enable them to communicate more effectively [8]. Central to the use of tools and strategies to supplement the existing communication of people who have severe communication problems is the extent to which these methods can influence the messages sent by the individual. Authorship, and its attendant complexities, becomes particularly relevant in cases where individuals have severe disabilities and need to be physically supported by another (facilitator) in an attempt to assist the person to formulate messages.

\section{Facilitated Communication, Authorship and Justice}

The issue of authorship of communication became of particular concern with the implementation of a strategy, Facilitated Communication (FC) which was first introduced and widely used by Rosemary Crossley (Australia) and subsequently by Douglas Biklen (Syracuse University, US) in the 1990s [9]. FC is a strategy in which physical, communicative and emotional support is provided by a facilitator, to assist individuals with severe disabilities to identify symbols (e. g. letters and graphic symbols) to communicate.

Experimental research on FC has focused almost exclusively on issues related to validation and authorship [9]. These studies rely heavily on blind procedures in which communicators are asked to convey information in ways that preclude facilitators from influencing message content. The results of this research have consistently failed to support the validity of Facilitated Communication, providing examples of facilitators who unknowingly influenced the content of the messages. The facilitators generally believed that the messages were conveyed by the user. Janyce Boyton [10] a past facilitator, wrote an article entitled "Facilitated Communication - What Harm It Can Co: Confessions of a Former Facilitator" in which she described the process through which she got involved in the use of FC:

In the beginning, I noticed my own movements. I felt that there were instances when I moved the child's arm, but I attributed it to my novice status and renewed my efforts not to influence the child's communications - as if wanting it to happen would make it so. The ed tech and I began seeing signs that FC was "working." We got "yes" or "no" answers, obtained by supporting Betsy's arm as she pointed to a letter board, and short 3-4-word sentences. I felt, for the first time, that I was making a connection with a student who had proved one of the most difficult on my caseload. We were convinced that these messages were coming from the child-in part because, the more practice we had as facilitators, the more fluid the "communications" became. At times, Betsy even reached for my hand when I offered it. Her seeming willingness to facilitate strengthened my belief that she wanted to participate in the activity and that FC was helping her to say what she wanted to say. [10, p. 4-5].

Boyton further describes her agony in having to come to terms with the fact that there was no clear evidence that supported any intentional communication by Betsy. Approximately 15 years after the first issues arose with 
Facilitated Communication in US courts in 1994, a resurgence of the use of the strategy was brought to the attention of the executive committee of the International Society for Augmentative and Alternative Communication (ISAAC). In response, ISAAC [11] brought out a position statement to caution against the use of the strategy. In spite of these events, however, FC is still used by some practitioners.

Recently in an American court case [12], a jury convicted a 45-year-old woman of sexually assaulting a 34-year-old male (DJ) with cerebral palsy who is unable to speak but used Facilitated Communication. Even though the defendant claimed that they were in love, the jury determined that DJ was unable to give consent. The convicted person is a college professor with no prior criminal record, and is facing between 10-40 years in state prison in New Jersey. The claimants in the case were the family of the young man.

The case underlines the blending of law and ethics, and as Scott [13] points out, conduct that breaches ethics often constitutes a violation of law, and visa versa. In this case, the jury found that becoming sexually involved with DJ without his consent constituted a violation of his rights, and is therefore punishable by law. The fact that DJ was unable to express himself independently of others was central to this decision. The challenge can therefore be framed in terms of how to ensure the "undistorted first word of the Other" [2, p.53] without the intentional or unintentional manipulation of others. The significant social media reporting that ensued about this case (e. g. http:/julieswritings.blog.com/2015/09/13some-of-mythoughts-on-the-anna-stubblefield-case/) necessitates an increased awareness of the ethics of communication and the continued need to identify, challenge and reconstitute the process of dialogue itself to more adequately acknowledge and engage the Other.

\section{In Conclusion}

This article focused on the importance of engagement of others as an essential part of ethics and justice. It highlighted the difficulties involved in this process by applying some of the concepts in Levinas' theory of ethics both to the problem of Alzheimer's and the ensuing anxiety around memory loss in Western society, as well to the use of Facilitated Communication for people with little or no speech. Man is responsible for the Other; this manifests as an ethical obligation to engage the Other. How this engagement of the Other translates into practice is complicated, but it is essential in working towards ethical practice. Only by acknowledging our conscience can we continue to find new and unobtrusive ways of engaging.

\section{References}

[1] Levinas, E. (1950). Ethics and infinity: translated by Richard A. Cohen. Pittsburgh, PA: Duquesne University Press.

[2] Murray, J. (2003). Face to Face in Dialogue: Emmanuel Levinas and the Communication of Ethics. Maryland: University Press of America.

[3] Johannesen, R; Valde, K \& Whedbee, K. (2008). Ethics in Human Communication. Long Grove: Waveland Press.

[4] Tavani, H. (2004). Ethics and Technology. Hoboken: John Wiley.

[5] Verde, M. (2011) June, 16. Communication and ethics interpolations (Electronic mailing message) Retrieved from www.iu.exchange.edu.

[6] Kitwood, T. (1997). Dementia reconsidered: The person comes first. Buckingham, England Philadelphia: Open University Press.

[7] Gullette, M M. (2011, May 21). Our Irrational Fear of Forgetting. New York Times. Retrieved from http://www.nytimes.com/2011/05/22/opinion/22gullette.html? _r $=1 \&$ scp= $=1 \&$ sq="May\%202.

[8] Tonsing, K; Alant, E \& Lloyd, L. L (2005). Augmentative and Alternative Communication. In Alant, E \& Lloyd, L. L (Eds). Augmentative and Alternative Communication: Beyond Poverty. London: Whurr Publishers., pp30-67.

[9] ASHA Technical Report: Facilitated Communication (1994). Retrieved from http://www.asha.org/policy/TR199400139.htm\#sec1.2, October, 202015.

[10] Boyton, J. (2012). Facilitated Communication- What harm it can do: Confessions of a Former Facilitator. Evidence-Based Communication Assessment and Intervention, 6(1), 3-13. http://dx.doi.org/10.1080/17489539.2012.674680

[11] ISAAC, 2014. Position Statement on Facilitated Communication. Augmentative and Alternative Communication, $\quad 30 \quad$ (4), 357-8. Doi: 10.3109/07434618.2014.971492.

[12] Engber, D. (2015, October, 22). The Strange Case of Anna Stubblefield. The New York Times, http://www.nytimes.com/2015/10/25/magazine/the-strangecase-of-anna-stubblefield.html?emc $=$ eta $1 \& \_r=0$, retrieved on October, 232015.

[13] Scott, R. 1998. Professional Ethics: A Guide for Rehabilitation Professionals. Toronto: Mosby. 